\title{
Isolated Limb Perfusion with Tumor Necrosis Factor and Melphalan for Limb Salvage in 186 Patients with Locally Advanced Soft Tissue Extremity Sarcomas
}

\section{The Cumulative Multicenter European Experience}

\author{
Alexander M. M. Eggermont, M.D., Ph.D., ${ }^{\star}$ Heimen Schraffordt Koops, M.D., Ph.D., $\dagger$ \\ Joseph M. Klausner, M.D.,‡ Bin B. R. Kroon, M.D., Ph.D.,§ Peter M. Schlag, M.D., Ph.D.,\| \\ Danielle Liénard, M.D., I Albertus N. van Geel, M.D., Ph.D., ${ }^{\star}$ Harald J. Hoekstra, M.D., Ph.D., $†$ \\ Isaac Meller, M.D.,‡ Omgo E. Nieweg, M.D., Ph.D.,§ Christoph Kettelhack, M.D.,\| \\ Gur Ben-Ari, M.D.,\# Jean-Claude Pector, M.D., Ph.D., ${ }^{\star \star}$ and Ferdy J. Lejeune, M.D., Ph.D.ף
}

From the Departments of Surgical Oncology, University Hospital Rotterdam, ${ }^{\star}$ Daniel den Hoed Cancer Center, Rotterdam, The Netherlands; University Hospital Groningen, $\dagger$ Groningen, The Netherlands; Ichilov Hospital, $\ddagger$ Tel Aviv, Israel; Netherlands Cancer Institute, § Amsterdam, The Netherlands; Robert Rössle Cancer Center, \| Umboldt University, Berlin, Germany; Centre Pluridisciplinaire d'Oncologie, $\mathbb{C H U V}$, Lausanne, Switzerland; Chaim Sheba Medical Center,\# Tel Hashomer, Israel; and Institut Jules Bordet, ${ }^{\star \star}$ Brussels, Belgium

\section{Objective}

The objective of the study was to achieve limb salvage in patients with locally advanced soft tissue sarcomas that can only be treated by amputation or functionally mutilating surgery by performing an isolated limb perfusion (ILP) with tumor necrosis factor (TNF) + melphalan $(\mathrm{M})$ as induction biochemotherapy to obtain local control and make limb-sparing surgery possible.

\section{Summary Background Data}

To increase the number of limb-sparing resections in the treatment of locally advanced extremity soft tissue sarcoma, preoperative radiation therapy or chemotherapy or a combination of the two often are applied. The ILP with cytostatic agents alone is another option but rarely is used because of rather poor results. The efficacy of the application of TNF in ILP markedly has changed this situation.

\section{Methods}

In 8 cancer centers, 186 patients were treated over a period of almost 4.5 years. There were $107(57 \%)$ primary and $79(43 \%)$ recurrent sarcomas, mostly high grade (110 grade III; 51 grade II; and 25 very large, recurrent, or multiple grade I sarcomas). The composition 
of this series of patients is unusual: 42 patients (23\%) had multifocal primary or multiple recurrent tumors; median tumor size was very large $(16 \mathrm{~cm}) ; 25$ patients $(13 \%)$ had known systemic metastases at the time of the ILP. Patients underwent a 90-minute ILP at 39 to $40 \mathrm{C}$ with TNF + melphalan. The first 55 patients also received interferon- $\tau$. A delayed marginal resection of the tumor remnant was done 2 to 4 months after ILP.

\section{Results}

A major tumor response was seen in $82 \%$ of the patients rendering these large sarcomas resectable in most cases. Clinical response rates were: 33 complete response (CR) (18\%), 106 partial response (PR) (57\%), 42 no change (NC) (22\%), and 5 progressive disease (PD) (3\%). Final outcome was defined by clinical and pathologic response: 54 CR (29\%), 99 PR (53\%), $29 \mathrm{NC}(16 \%)$, and 4 PD (2\%). At a median follow-up of almost 2 years (22 months; range, 6-58 months), limb salvage was achieved in $82 \%$. Regional toxicity was limited and systemic toxicity minimal to moderate, easily managed, with no toxic deaths.

\section{Conclusions}

In the setting of isolated limb perfusion, TNF is an active anticancer drug in patients. The ILP with TNF + melphalan can be performed safely in many centers and is an effective induction treatment with a high response rate that can achieve limb salvage in patients with locally advanced extremity soft tissue sarcoma.

Management of locally advanced extremity soft tissue sarcomas (STSs) that leads to an increase in preservation of functional limbs continues to be a challenge. Although control and prevention of distant metastases is a major concern, limb salvage has become all the more important in light of evidence that amputations do not improve survival rates in patients with large $(>5 \mathrm{~cm})$ deep-seated high-grade sarcomas. ${ }^{1}$ Local recurrence rates vary according to the initial surgical procedure, and improved local control has been reported to correlate with better survival. ${ }^{2}$ Several recent studies, however, show that marginal excisions with a high risk for local recurrence do not influence survival significantly. ${ }^{1,3-6}$ Of the 6000 new cases of STS diagnosed in the United States each year, approximately 3600 occur in the extremities and tumors are often large at the time of diagnosis. ${ }^{7}$ Treatment options for locally advanced extremity STS may consist of an amputation or a limb-sparing extensive surgical procedure followed by radiation therapy. This combination may mutilate and compromise limb function considerably. Preoperative therapies to improve limb salvage rates have been propagated. Suit et al. ${ }^{8}$ reported already in 1981 on the use of preoperative radiation therapy. Eilber et al. ${ }^{9,10} \mathrm{com}-$ bined preoperative (intra-arterial or systemic) chemotherapy and radiation therapy to improve resectability rates.

Presented at the 3rd Annual Meeting of the European Surgical Association, Paris, May 3-4, 1996.

Address reprint requests to Alexander M. M. Eggermont, M.D., Ph.D., Department of Surgical Oncology, University Hospital Rotterdam, Daniel den Hoed Cancer Center, 301 Groene Hilledijk, 3075 EA Rotterdam, The Netherlands.

Accepted for publication June 20, 1996.
Amputation also may be avoided and local control improved by applying brachytherapy techniques to the tumor bed in the context of marginal resections. ${ }^{11}$ Yet another strategy is to perform an isolated limb perfusion (ILP) with cytostatic agents. This technique, first described by Creech et al., ${ }^{12}$ exposes tumors to drug concentrations 20 times higher than after systemic therapy ${ }^{13}$ to maximize tumor reduction. Melphalan, the standard drug for ILP in the treatment of melanoma, ${ }^{14}$ also has been used in the treatment of extremity STS, but with rather poor results. ${ }^{15-20}$ Doxorubicin and other drugs have been reported to yield similar disappointing results in ILP for STS. ${ }^{21-23}$ Lejeune and Liénard ${ }^{35}$ pioneered the application of tumor necrosis factor (TNF) in ILP and reported high complete response (CR) rates not only in patients with stage III melanoma but remarkably also in four patients with advanced extremity STS. ${ }^{24}$ This observation led to a multicenter study in eight centers in Europe. Here we report on this unique experience in 186 patients with advanced extremity STS.

\section{PATIENTS AND METHODS}

Between May 1991 and November 1995, a total of 186 patients ( 97 men, 89 women; median age, 47 years; range, 13-82) with locally advanced extremity STS were treated. The composition of this series of patients is unusual and shows that most patients were referred because amputation was considered the only option. A total of 200 ILPs were performed in these 186 patients as 9 patients received a second ILP within 3 months after the first ILP to improve the initial response. Four patients underwent a second ILP for a local recurrence, and one patient with 
Table 1. CHARACTERISTICS OF 186 PATIENTS WITH LOCALLY ADVANCED SOFT TISSUE SARCOMAS

\begin{tabular}{lc}
\hline \multicolumn{2}{c}{ Characteristic } \\
\hline Male/female & $97 / 89$ \\
Median age (yrs) (range) & $47(13-82)$ \\
Legs/arms & $153 / 33$ \\
Single tumor & $143(77 \%)$ \\
Multiple tumors (range 2->100) & $43(23 \%)$ \\
Median size tumor (cm) (range) & $16(2-38)$ \\
Primary sarcomas & $107(57 \%)$ \\
Local recurrences & $79(43 \%)$ \\
Known distant metastases at time ILP & $25(13 \%)$ \\
& \\
ILP = isolated limb perfusion.
\end{tabular}

$>100$ tumors underwent a second and a third ILP for a local (re)recurrence. Here we report on the results of the initial treatment consisting of a single ILP in 177 patients and of a double ILP in 9 patients. There were 107 (57\%) primary and $79(43 \%)$ recurrent sarcomas. Sarcomas were located in the leg in 153 and in the arm in 33 patients.

\section{Criteria of Irresectability or Locally Advanced Stage}

All patients were referred to the eight participating cancer centers because the sarcomas were considered irresectable or could only be resected at the cost of major functional morbidity because of the following tumor-associated criteria: multifocal primary tumors or multiple recurrent tumors in the limb; single tumors with fixation to or invasion into the neurovascular bundle and/or bone; tumor recurrences in previously radiated areas with no possibility for a radical resection. Radical resections, that is, resections with a margin of healthy tissue, were, based on clinical examination and computed tomography and magnetic resonance imaging scans, impossible in all patients. A team of specialists in the cancer centers that all have a large sarcoma referral position agreed on the indication for a TNF-based ILP in these patients. A single large tumor (median size, $16 \mathrm{~cm}$ ) was present in 143 patients (77\%); in 43 patients (23\%), there were multiple lesions in the extremity (range, 2->100); 25 patients (13\%) had known systemic metastases at the time of ILP. Patient characteristics are summarized in Table 1.

Apart from tumor-associated criteria as defined above, inclusion and exclusion criteria included the following: age, 12 to 80; patient informed consent, patients must have no severe cardiopulmonary disease, no uncontrolled infections, no organ transplants, no concurrent immunosuppressive therapy, no concurrent chemotherapy, immu-
Table 2. HISTOLOGIC TYPES OF SOFT TISSUE SARCOMAS IN 186 PATIENTS

\begin{tabular}{lc}
\multicolumn{1}{c}{ Type of Sarcoma } & $\mathbf{n}$ \\
\hline Malignant fibrous histiocytoma (MFH) & 47 \\
Liposarcoma & 36 \\
Synoviosarcoma & 27 \\
Leiomyosarcoma & 13 \\
Malignant schwannoma & 13 \\
Angiosarcoma (hemangio/lymphangio) & 10 \\
Rhabdomyosarcoma & 7 \\
Fibrosarcoma & 6 \\
Clear cell sarcoma & 5 \\
Neurofibrosarcoma & 4 \\
Epithelioid sarcoma & 4 \\
Desmoid tumors & 4 \\
Neurogenic sarcoma & 2 \\
Hemangiopericytoma & 2 \\
Alveolair MFH & 1 \\
Extraosseous Ewing sarcoma & 1 \\
Chondro soft tissue sarcoma & 1 \\
Soft tissue osteosarcoma & 1 \\
Kaposi sarcoma & 1 \\
Unclassified sarcoma & 1 \\
Total & 186 \\
\hline
\end{tabular}

notherapy, radiation therapy, no coagulation disorder, no severe obliterative peripheral arteriosclerosis, no severe lymphedema in the extremity.

\section{Histologic Type and Grade of Sarcomas}

There were 20 different histologic types that are summarized in Table 2. Tumor grading data are summarized in Table 3. Most (161/186) tumors were high grade tumors (110 grade III, 51 grade II), and there were 25 grade I sarcomas (always very large, recurrent, or multiple); Grading was according to Trojani et al. ${ }^{25}$ In brief, summation of the scores of the three most important histopathologic characteristics of the tumor determines grading as follows: 1) mitosis count at $\mathrm{G} \times 400 / 10$ fields: 0 to 9 , score $1 ; 10$ to 20 , score 2 ; and $>20$, score $3 ; 2$ ) tumor differentiation: well, moderately, or poorly differentiated

Table 3. HISTOLOGIC GRADING OF SOFT TISSUE SARCOMAS IN 186 PATIENTS

\begin{tabular}{lr}
\hline Grade & $\mathbf{n}$ \\
\hline I & 25 \\
II & 51 \\
III & 110 \\
Total & 186 \\
\hline
\end{tabular}


corresponds with scores 1,2 , and 3 , respectively; 3 ) tumor necrosis: no, $<50 \%$, and $>50 \%$ necrosis corresponds with scores 0,1 , and 2 , respectively. Grade I has a total score of 2 or 3 , grade II has a total score of 4 or 5 , and grade III has a total score of 6,7 , or 8 .

\section{Drugs and Treatment Schedule}

Recombinant human TNF- $\alpha$ (TNF, $0.2 \mathrm{mg} / \mathrm{ampule}$, 4.9-5.8 $\times 10^{7}$ units $/ \mathrm{mg}$ ) and recombinant human interferon-gamma (IFN, $0.2 \mathrm{mg}$ or $1.5 \times 10^{6}$ units/ampule) were a gift from Boehringer Ingelheim $\mathrm{GmbH}$, Ingelheim/ Rhein, Germany. Melphalan (L-Pam, Alkeran, Wellcome Ltd., London, UK) was obtained as a sterile powder (100 $\mathrm{mg}$ ) that was dissolved aseptically using solvent and diluent provided by Burroughs Wellcome (London, England). Only the first 55 patients also received $0.2 \mathrm{mg}$ IFN subcutaneously on the 2 days before the ILP and the same dose in the perfusion circuit. As IFN has some toxicity in terms of fever, headaches, nausea, myalgia, and arthralgia and was not believed to be an essential component of the treatment (see discussion section), it was left out of the protocol after the first 55 patients. The ILP was carried out under general anesthesia and took normally 4 to 5 hours. Isolated limb perfusion procedures have been standardized in all centers, and all centers have been visited as part of an internal quality control program. Briefly, isolation of the blood circuit of a limb was achieved by clamping the major artery and vein, by ligating the collateral vessels, and by applying a tourniquet to compress the remaining minor vessels in cutis, subcutis, and muscles. Perfusion was carried out at the axillary, brachial, iliac, femoral, or femoropopliteal level. To obtain the proximal (axillary or iliac) isolation level, a pin was inserted into the head of the humerus or iliac crest; an occluding rubber bandage was fixed around the pin and twisted around the root of the extremity. To obtain the distal (brachial or femoropopliteal) isolation level, an inflatable tourniquet was used. The ILP consisted of a 90 -minute long perfusion, 3 (arm) to 4 (leg) $\mathrm{mg} \mathrm{TNF}$, and $10 \mathrm{mg} / \mathrm{L}$ leg or 13 $\mathrm{mg} / \mathrm{L}$ arm volume of melphalan at mild hyperthermia (39-40 C). Composition of the perfusate included the following: priming volume of 700 to $850 \mathrm{~mL}$ consisted of 400 to $500 \mathrm{~mL}$ blood (50\% erythrocytes, 50 plasma), 200 to $400 \mathrm{~mL} 5 \%$ dextran 40 in glucose $5 \%$ (Isodex, Pharmacia, Uppsala, Sweden) of Haemaccel (Behring Pharma, Amsterdam, The Netherlands), 10 to $30 \mathrm{~mL} 8.4 \%$ sodium bicarbonate, and $0.5 \mathrm{~mL} 2500$ to 5000 international units heparin. The TNF was injected as a bolus into the arterial line provided limb tissue temperature was $>38$ C. Melphalan was administered 30 minutes later at limb temperatures between 39 and $40 \mathrm{C}$. At the end of ILP, the limb was washed with at least $1 \mathrm{~L}$ of Haemaccel and $1 \mathrm{~L}$ of $6 \%$ dextran 70 (Macrodex, Pharmacia, Upp- sala, Sweden). Flow rates during the perfusion were kept at physiologic levels of 40 to $50 \mathrm{~mL} / \mathrm{minute} / \mathrm{L}$ limb volume. Flow rates could be adjusted (reduced) in the case of slow leakage from the limb-perfusion circuit to the systemic compartment provided oxygen saturation levels in the perfusate remained adequate $(>65 \%)$. Perfusate blood gas levels were monitored continuously for oxygen saturation. Every 30 minutes, $\mathrm{pO}_{2}$ and partial pressure of carbon dioxide $\left(\mathrm{pCO}_{2}\right)$ levels were checked as well as lactate levels and the $\mathrm{pH}$, which was kept at a $\mathrm{pH}>7,25$ by adding sodium if necessary. There was continuous monitoring of the temperature in the subcutaneous and intramuscular distal and proximal compartments of the limb using thermistor needle probes.

\section{Leakage Monitoring}

During limb perfusion, there was a dynamic balance between two pressure compartments, the systemic vasculature and the isolated circuit, which could be influenced by adjusting the systemic blood pressure or the extracorporeal flow rate or both. Throughout the perfusion period, any potential leakage of the drugs was monitored using a radioactive tracer. A small calibration dose of human serum albumin radiolabelled with ${ }^{131} \mathrm{I}$ or ${ }^{99 \mathrm{~m}} \mathrm{Tc}$ was injected into the systemic circulation and a (tenfold) higher dose of the same isotope into the isolated extremity. Continuous monitoring was performed with a precordial scintillation probe. Systemic leakage was expressed quantitatively as a percentage (100\% leakage representing a homogeneous distribution of the isotope in the body). ${ }^{26}$

\section{Cardiopulmonary and Hemodynamic Monitoring}

Perioperative monitoring consisted in the early phase of the study of electrocardiogram, urine output, blood pressure, venous and pulmonary pressures, and arterial wedge pressures. This was later only done in high-risk patients. Similarly, the routine administration of low-dose dopamine perioperatively was abandoned. Fluid loading was applied during the operation before releasing the tourniquet after completion of the washout of the limb.

\section{Assessment of Tumor Response}

Clinical responses were as follows: Complete remissions (CR: disappearance of all measurable disease in the limb for $>4$ weeks), partial remissions (PR: regression of the tumor size by more than $50 \%$ for $>4$ weeks), no change (NC: regression less than $50 \%$ of the tumor in the limb or progression less than $25 \%$ for $>4$ weeks), and progressive disease (PD: progression more than 25\%) were assessed by standardized World Health Organization 
criteria. ${ }^{27}$ Extensive histopathologic examinations of the resected specimens were performed. The percentage of necrosis was estimated on the basis of macroscopic evaluation of necrotized tissue and histologic examination results of tissue surrounding the necrotic area, tissue without identifiable nuclei being considered necrotic. If clinically no tumor was detectable anymore (clinical CR) but resection of the tumor bed showed vital tumor cells, the final outcome was downgraded to a PR. A clinical PR could only be upgraded to a CR if histologic analysis showed $100 \%$ necrosis of the tumor remnant. Likewise, a clinical minimal regression of $<50 \%$, but still rendering the tumor resectable, could be upgraded to a PR if the tumor remnant was found to be necrotic for $50 \%$ or more. A clinical regression of $>50 \%$ would qualify for a PR even if necrosis in the tumor remnant would be $<50 \%$, as $>50 \%$ of the tumor mass had disappeared.

\section{Marginal Resection of the Tumor Remnant}

Resections of the tumor remnants were performed between 4 and 24 weeks after ILP (average of 10 weeks). Usually this period allowed for enough shrinkage of the tumor to become mobile or shrink for more than $50 \%$. The least of margins usually was not more than $1 \mathrm{~mm}$, and all resections were marginal resections ("shell out" procedures). Tumors usually were still large, but after ILP, were often surrounded by a thickened fibrous capsule bordering on bone or neurovascular structures.

\section{Assessment of Toxicity}

Systemic toxicity was graded by the Eastern Cooperative Oncology Group-World Health Organization grading. ${ }^{27}$ Regional toxicity was graded according to Wieberdink et al. $^{28}$ : 1 = no toxicity, $2=$ redness and slight edema, 3 = considerable erythema or edema with some blistering; slightly disturbed mobility possible, 4 = extensive epidermolysis or obvious damage to the deep tissues, causing definite functional disturbances; threatening or manifest compartmental syndrome, and $5=$ reaction requiring amputation.

The protocol was approved by all local ethical committees. Informed consent was obtained from all patients before treatment.

\section{RESULTS}

\section{Tumor Response and Limb Salvage}

A major tumor response was seen in $82 \%$ of the patients, rendering most of these large sarcomas resectable. The key parameters defining outcome of treatment, clini-

\begin{tabular}{|c|c|c|}
\hline Table 4. & $\begin{array}{l}\text { OUTCOME OF TREAT } \\
186 \text { PATIENTS* }\end{array}$ & VT IN \\
\hline $\begin{array}{l}\text { Clinical Response } \\
\qquad(n=186)\end{array}$ & $\begin{array}{l}\text { Histologic Response } \\
\text { (\% necrosis) }(n=148)\end{array}$ & $\begin{array}{l}\text { Final Outcome } \\
\qquad(n=186)\end{array}$ \\
\hline 33 CR (18\%) & $48 \mathrm{CR}$ & 54 CR (29\%) \\
\hline 106 PR (57\%) & 73 PR & 99 PR (53\%) \\
\hline 42 NC (22\%) & $27 \mathrm{NC}$ & 29 NC (16\%) \\
\hline 5 PD (3\%) & 38 ND & 4 PD (2\%) \\
\hline \multicolumn{3}{|c|}{$\begin{array}{l}\text { ND }=\text { not done; } C R=\text { complete response; } P R=\text { partial response; } N C=\text { no } \\
\text { change; } P D=\text { progressive disease. } \\
\text { Limb salvage at median follow-up of } 22 \mathrm{mo}, 152 / 186=82 \% \text {. } \\
{ }^{*} \text { Clinical response: CR } 100 \% \text { regression; PR }>50 \% \text { regression; NC }<50 \% \\
\text { regression; PD progression. Pathologic response: CR } 100 \% \text { necrosis; PR } 50- \\
99 \% \text { necrosis; NC }<50 \% \text { necrosis. }\end{array}$} \\
\hline
\end{tabular}

cal and pathologic response, final outcome of treatment, and limb salvage rate are summarized in Table 4. Clinical response rates were as follows: $33 \mathrm{CR}(18 \%), 106 \mathrm{PR}$ $(57 \%), 42 \mathrm{NC}(22 \%)$, and 5 PD (3\%). Final outcome as defined by clinical and pathologic response was as follows: 54 CR (29\%), 99 PR (53\%), 29 NC (16\%), and 4 PD (2\%). At a median follow-up of almost 2 years (22 months) (range, 6-58 months), limb salvage was achieved in $82 \%$ (152 patients). In 126 patients with a single tumor, the tumor remnant was resected and a local recurrence developed after 3 to 24 months in 14 patients (11\%). In the other 60 patients, no resection was performed (multiple tumors, systemic metastases, refusal to be amputated), local tumor control was obtained in 33 patients (55\%), and recurrences occurred in 27 patients (45\%). Limb salvage often was still achieved as patients were already dying of systemic disease. Additional radiation therapy was given in only $39(21 \%)$ of 186 patients.

\section{Repeat Perfusions}

Nine patients underwent two perfusions, scheduled 6 to 10 weeks from each other to convert a PR (or NC) into a better response. In six patients, a PR was converted into an CR; in two patients, a PR into a better PR, and in one patient, NC remained NC. Four patients had a second limb perfusion for a local recurrence 12 to 18 months after the first ILP + resection. One patient with $>100$ tumors in her left forearm, wrist, and hand underwent three perfusions at intervals of 1.0 to 1.5 years because of locally recurrent disease after a CR and longlasting PR.

\section{Amputations}

In 34 patients (18\%), the limb had to be amputated. Four patients underwent an amputation despite having a 
histologically confirmed CR. One patient had to be amputated early because of necrosis of a previously heavily irradiated foot and another because tumor involvement of the lower leg was so extensive that after resection of all the necrosis, there was no tissue left to have a viable lower leg. There were two late amputations: in one patient in whom after delayed resection of a $100 \%$ necrotic tumor mass developed osteomyelitis because of a period of inadequate soft tissue coverage of the bone ending in a pathologic fracture 17 months after ILP; the second patient underwent an amputation 21 months after ILP despite a CR but due to recurrent ulceration and erysipelas after adjuvant irradiation. All other amputations were done because of insufficient response to the ILP or because of local tumor recurrence 4 to 24 months after ILP.

\section{Systemic Metastasis and Survival}

In 25 patients $(13 \%)$, synchronous metastases were present at the time of ILP; limb salvage was achieved in 23 patients $(92 \%)$ and 20 patients $(80 \%)$ have died (median, 9 months); at a median follow-up of almost 2 years, metachronous distant metastases appeared after ILP in 58 $(36 \%)$ of 161 patients; $44(27 \%)$ of these 58 patients have $\operatorname{died}(44 / 58=76 \%)$.

\section{Regional Toxicity}

Regional toxicity was scored according to Wieberdink et al. ${ }^{28}$ and found to be moderate. Almost all patients (171 patients) had a perfusion reaction grade II and III. This is similar to the toxicity observed after ILP with melphalan alone. Grade IV toxicity developed in 14 patients. In one patient, grade $\mathrm{V}$ toxicity required amputation of an irradiated foot. Transient paraesthesia (fingertips, toes) occurred in $20 \%$ of the patients. Transient motor neurapraxia of less than 6 months was observed in $8 \%$ and long-lasting motor-neurapraxia (mostly peroneal nerve) was observed in $3 \%$.

\section{Systemic Toxicity}

Systemic toxicity was moderate and easily manageable. Almost all patients had fever, sometimes with chills, within 4 hours of the ILP, treated effectively with paracetamol or indomethacin. The following events were reviewed and did not require therapeutic interventions:

1. Cardiovascular. A hyperdynamic state developed in most patients and went through a phase of slightly lowered blood pressure, easily managed by administering fluid and not requiring the administration of vasopressor drugs. A significant transient drop in blood pressure (grades III-IV) occurred in six patients $(3 \%)$.

2. Pulmonary. Adult respiratory distress syndrome occurred in only one patient $(0.5 \%)$.

3. Renal. Creatinine levels remained normal in most patients, but one patient experienced transient grade IV renal toxicity $(0.5 \%)$.

4. Hepatic. Hepatic toxicity was very modest and mainly reflected in an isolated transient rise in transaminases. Grade III and IV peak levels of the aspartate transaminase and alanine transaminase were seen in 17 patients (9\%).

5. Hematologic. Transient grades III and IV leukopenia occurred in six patients and grade III and IV thrombocytopenia occurred in eight patients (usually around day 3 ).

\section{DISCUSSION}

This report on our multicentric experience with TNFbased isolated limb perfusions in the management of locally advanced extremity STS in 186 patients represents by far the largest experience in the world.

The $29 \%$ CR rate, $53 \% \mathrm{PR}$ rate, and the $82 \%$ limb salvage rate at a median follow-up of almost 2 years in this group of patients with unusually advanced disease (median size, $16 \mathrm{~cm}$; multiple tumors in 23\%) show the efficacy of this two-step approach to achieve limb salvage.

It is hard to find comparable series of patients with comparably advanced tumors. Krementz et al. ${ }^{15}$ described in 39 patients with extremity STS (resectable, smaller median size) only 4 CRs (10\%) and 8 PRs (21\%) after ILP with melphalan \pm nitrogen mustard \pm actinomycinD. In 17 patients with irresectable sarcomas and a delayed resection after ILP, 0 CR (0\%) and only 6 PRs (35\%) were observed. ${ }^{15}$ These results are quite inferior to ours. Most reports on the use of ILP in STS concern adjuvant ILPs. ${ }^{16-19}$ For sarcomas, ILP with doxorubicin may seem attractive, but its use was reported to cause considerable regional toxicity and to be ineffective when used alone. ${ }^{20,21}$ In a series of 26 patients, a $0 \%$ response rate was seen in 22 grade II and III sarcomas with 3 amputations because of toxicity, whereas 4CRs were observed only in patients with low grade sarcomas and only when doxorubicin was combined with melphalan. ${ }^{21}$ In a recent study, $>50 \%$ necrosis in STS tumors after ILP with doxorubicin was observed in 16 of 23 patients, but no clinical response data were provided and, more importantly, no complete remissions were observed. ${ }^{22}$ Others reported high local recurrence rates and amputation rates up to $41 \%$ after ILP with melphalan in combination with other cytostatic agents. ${ }^{23}$ Overall, it seems fair to conclude that the addition of TNF markedly improves results and con- 
clude, thereby, that TNF is active and apparently a crucial agent in this application in humans.

Other multimethod approaches such as the combination of preoperative intra-arterial infusions with doxorubicin and radiation therapy after resection of the STS also may result in excellent local control rates, but these are achieved in rather unselected and, thus, differently composed patient populations. ${ }^{9,10}$ Again, publications on patients with disease as advanced as in this series are very hard to find. A recent publication on this preoperative approach by Wanebo et al. ${ }^{29}$ illustrates this point, as in their series of 66 patients, median tumor size was only 7 $\mathrm{cm}$ (versus $16 \mathrm{~cm}$ ), and local wide resections (margins of $2-4 \mathrm{~cm}$ of normal tissue) were possible in $58 \%$, whereas these wide resections were not possible in our patients. Other approaches to increase limb salvage are preoperative radiation therapy, ${ }^{8}$ marginal resections in combination with brachytherapy, ${ }^{11}$ and neoadjuvant chemotherapy. ${ }^{30}$ Suit et al. ${ }^{8}$ reported on a favorable outcome using preoperative radiation therapy followed by limbsparing surgery. Tumors were, however, smaller than in our series. Induction chemotherapy was reported to yield a $6 \%$ CR and a $32 \%$ PR rate by Rouësse et al. ${ }^{30}$ These results clearly seem inferior to the results achieved by TNF-based ILP. Shiu et al. ${ }^{11}$ reported on the quite successful brachytherapy program at the Memorial Sloan Kettering Hospital. With a $70 \%$ local control rate in patients with sarcomas abutting the neurovascular bundle, their results may resemble the efficacy reported by us using TNF-based ILP. Obviously, only a randomized trial comparing the various approaches would give an answer as to which methods are most appropriate and in which patients. The ILP with TNF + melphalan seems of particular palliative value in the patients with widespread metastatic disease and an uncontrollably rapidly growing tumor, threatening the limb. In all but 2 of 25 of such patients, a single ILP provided rapid and life-lasting (up to $>2$ years) local control.

The local recurrence rate of $11 \%$ in 126 patients with a single tumor and a delayed resection is low considering the following: large median tumor size, the percentage of recurrent sarcomas treated, and the conservative surgical procedures, followed only in $21 \%$ of the patients by additional radiation therapy. These patients had microscopically irradical resections. Because of the size of the irradiation field and/or the involvement of knee or elbow joints, irradiation in many patients was not added to the perfusion and delayed resections for the fear of inflicting too much local toxicity and functional damage. Local recurrence rates probably can be further improved by giving postresection radiation therapy in a higher percentage of cases. In addition to histopathologic examinations, new techniques such as magnetic resonance spectroscopy and positron emission tomography scanning may be quite use- ful to assess the extent of necrosis and predict the quality of the response and, thus, influence clinical decision making regarding type and timing of the resection of the tumor as well as the decision to add radiation therapy. ${ }^{31,32}$ Recurrence rates were high in the 60 patients who did not undergo a delayed resection for reasons such as multiple tumors, pre-existing metastases, and metachronous metastasis, but local control in most cases was sufficient to be overtaken by rapid progression of systemic disease.

Our experience further shows that the procedure is safe and is associated with only little-to-moderate regional and systemic toxicity. Systemic toxicity is related to the leakage rate during the perfusion, and continuous leakage monitoring, as described, is mandatory to perfuse safely and be able to take corrective measures during the perfusion. ${ }^{33,34}$ Toxicity can be further reduced by prolonging the washout procedure at the end of the ILP. ${ }^{35}$

The publication of a small series of TNF + melphalan ILPs by Hill et al. ${ }^{36}$ is important in two respects: first, no IFN- $\tau$ was used and a $100 \%$ CR rate was observed in nine patients with soft tissue sarcoma; second, lower doses of TNF were used. The TNF levels in the perfusate varied from 0.5 to $0.75 \mu \mathrm{g} / \mathrm{mL}$, which is approximately fivefold to sixfold lower than the levels usually observed in the perfusates in our trial $(3-5 \mu \mathrm{g} / \mathrm{mL})$. This suggests that lower doses of TNF- $\alpha$ than used by us can be applied successfully. It is of importance to note, however, that also TNF concentrations of 0.50 to $0.75 \mu \mathrm{g} / \mathrm{mL}$ can only be obtained by ILP techniques. It will add obviously to the safety of the procedure if one can reduce the dose of TNF while retaining its antitumor effects. In our experience, IFN- $\tau$ does not seem to add to the antitumor effect of the procedure. The response and limb salvage rates in the first $\mathbf{5 5}$ patients were virtually identical to what has been observed in the following 131 patients treated without IFN, whereas systemic toxicity was somewhat more pronounced when IFN was used. ${ }^{37}$ The nonessential role of IFN also has been observed in a randomized phase II study in patients with locally advanced melanoma that we have carried out. ${ }^{38}$ Also in this study, more toxicity was observed in the IFN containing treatment arm. In a nonimmunogenic soft tissue sarcoma model in rats, ${ }^{39}$ we addressed also the question of the value of IFN and did not find enhancement of the antitumor effects compared to after ILP with TNF + melphalan but without IFN (Eggermont AMM, Rotterdam, personal communication, Cambridge Symposium, TNF and Related Cytokines, March 1996). It is clear that melphalan is crucial as ILPs with TNF- $\alpha$ alone do not induce any or only very shortlived responses in patients with melanoma, ${ }^{40}$ in patients with STS (Fraker DL, NCI Surgery Branch, Bethesda, $\mathrm{MD}$, personal communication, Cambridge Symposium, TNF and Related Cytokines, March 1996). In isolated limb perfusion models in different strains of rats using 
soft tissue sarcomas ${ }^{39,41}$ or osteosarcomas, ${ }^{42}$ it has been shown recently by the Rotterdam perfusion group that both melphalan and TNF are crucial to obtain antitumor effects, each agent alone being ineffective.

In contrast to the disappointing results of the systemic administration of TNF in humans in phase I and II trials, ${ }^{43-45}$ TNF may be applied successfully in humans in a setting where the tumor and tumor vascular bed can be exposed to very high concentrations. Apart from direct antitumor effects, ${ }^{46,47}$ TNF also has in humans mainly important indirect (vascular) antitumor effects such as thrombocyte aggregation, erythrostasis, endothelial, and vascular destruction as have been described by us. ${ }^{48-50}$ These observations resemble many of the phenomena reported in experimental tumor systems. ${ }^{51,52}$ These selective vasodestructive effects on tumor vessels can be shown elegantly by pre- and post-ILP angiographies. ${ }^{53}$ Neutrophils also may play an important role in the antitumor effects as extravasation and invasion of the tumor by neutrophils can be observed after ILP with TNF- $\alpha .{ }^{48} \mathrm{Ob}-$ servations in the sarcoma perfusion model in rats in our laboratory suggest strongly that both neutrophils and platelets play a crucial role as much of the TNF antitumor effect is lost in rats with severe radiation-induced neutropenia. ${ }^{54}$ The evidence that the common denominator, that is, the tumor vascular bed, is the target for TNF would predict that any histologic type of solid tumor is prone to be sensitive to the effects of TNF. This is exactly our experience as we have observed tumor responses in 20 types of sarcomas, melanomas, as well as in a range of other tumors in extremities (unpublished observations, 1991-1996). Thus, TNF eventually may be used successfully in a number of settings such as isolated lung, ${ }^{55}$ liver, ${ }^{56,57}$ or kidney ${ }^{58}$ perfusions in the treatment of a variety of tumors.

\section{CONCLUSIONS}

The ILP with TNF + melphalan is a new option in the management of locally advanced and irresectable soft tissue sarcomas of the extremities. The procedure is safe and is associated with a high response rate and a high limb salvage rate. It merits further evaluation in an increasing number of centers that deal with the treatment of soft tissue sarcomas to further define its value and place in the management of extremity tumors.

\section{References}

1. Gaynor JJ, Tan CC, Casper ES, et al. Refinement of clincopathologic staging for localized soft tissue sarcoma of the extremity:a study of 423 adults. J Clin Oncol 1992; 10:1317-1327.

2. Suit HD, Tepper JE. Impact of improved local control on survival in patients with soft tissue sarcoma. Int J Radiat Oncol Biol Phys 1986; 12:699-700.

3. Brennan MF, Shiu MH, Collin C, et al. Extremity soft tissue sarcomas. Cancer Treat Symp 1985; 3:71-81.

4. Potter DA, Kinsella D, Gladstein E, et al. High grade soft tissue sarcomas of the extremities. Cancer 1986; 59:190-205.

5. Stotter AT, A'Hearn RP, Fisher C, et al. The influence of local recurrence of extremity soft tissue sarcoma on metastasis and survival. Cancer 1990; 65:1119-1129.

6. Gustafson P, Rööser B, Rydholm A. Is local recurrence of minor importance for metastases in soft tissue sarcoma? Cancer 1991; 67:2083-2086.

7. Boring CC, Squires TS, Tong T, et al. Cancer Statistics, 1994. CA Cancer J Clin 1994; 44:7-26.

8. Suit HD, Proppe KH, Mankin HJ, et al. Preoperative radiation therapy for sarcoma of soft tissue. Cancer 1981; 47:2269-2274.

9. Eilber FR, Mirra JJ, Grant T, et al. Is amputation necessary for sarcoma: a 7-year experiment with limb salvage. Ann Surg 1980; 192:431-437.

10. Eilber FR, Morton DL, Eckhardt J, et al. Limb salvage for skeletal and soft tissue sarcomas: multidisciplinary preoperative therapy. Cancer 1984; 53:2579-2584.

11. Shiu MH, Hilaris BS, Harrison LB, et al. Brachytherapy and function-saving resection of soft tissue sarcoma arising in the limb. Int J Radiat Oncol Biol Phys 1991; 21:1485-1492.

12. Creech OJ, Krementz ET, Ryan RF, et al. Chemotherapy of cancer: Regional perfusion utilizing an extracorporeal circuit. Ann Surg 1958; 148:616-632.

13. Benckhuijsen C, Kroon BBR, Van Geel AN, et al. Regional perfusion treatment with melphalan for melanoma in a limb: evaluation of drug kinetics. Eur J Surg Oncol 1988; 14:157-163.

14. Thompson JF, Gianoutsos MP. Isolated limb perfusion for melanoma: effectiveness and toxicity of cisplatin comparred with that of melphalan and other drugs. World J Surg 1992; 61:227-233.

15. Krementz ET, Carter RD, Sutherland CM, Hutton I. Chemotherapy of sarcomas of the limbs by regional perfusion. Ann Surg 1977; 185:555-564.

16. McBride CM. Sarcomas of the limbs: result of adjuvant chemotherapy using isolation perfusion. Arch Surg 1974; 109:304-308.

17. Stehlin JS, de Ipolyi PD, Giovanella BC, et al. Soft tissue sarcomas of the extremity: multidisciplinary therapy employing hyperthermic perfusion. Am J Surg 1975; 130:643-646.

18. Lethi PM, Stephens MH, Janoff $\mathrm{K}$, et al. Improved survival for soft tissue sarcoma of the extremities by regional hyperthermic perfusion, local excision and radiation therapy. Surg Gynecol Obstet 1986; 162:149-152.

19. Hoekstra HJ, Schraffordt Koops H, Molenaar WM, et al. Results of isolated regional perfusion in the treatment of malignant soft tissue tumors of the extremities. Cancer 1987; 60:1703-1707.

20. Braat RP, Wieberdink J, van Slooten EA, et al. Regional perfusion with Adriamycin in soft tissue sarcomas. In: Schwemmle K, Aigner $\mathrm{K}$, eds. Vascular Perfusion in Cancer Therapy, Recent Results in Cancer Research. Vol. 86. Berlin: Springer-Verlag; 1983:260-263.

21. Klaase JM, Kroon BBR, Benckhuysen C, et al. Results of regional isolation perfusion with cytostatics in patients with soft tissue tumors of the extremities. Cancer 1989; 64:616-621.

22. Rossi CR, Vecchiato A, Foletto M, et al. Phase II study on neoadjuvant hyperthermic-antiblastic perfusion with doxorubicin in patients with intermediate of high grade limb sarcomas. Cancer 1994; 73:2140-2146.

23. Filippo FD, Calabro AM, Cavallari A, et al. The role of hyperthermic perfusion as a first step in the treatment of soft tissue sarcomas of the extremities. World J Surg 1988; 12:332-339.

24. Liénard D, Delmotte JJ, Renard N, et al. High doses of rTNF- $\alpha$ in 
combination with IFN-gamma and melphalan in isolation perfusion of the limbs for melanoma and sarcoma. J Clin Oncol 1992; 10:5260.

25. Trojani M, Contesso G, Coindre JM, et al. Soft-tissue sarcomas of adults; study of pathologic prognostic variables and definition of a histopathological grading system. Int J Cancer 1984; 33:37-42.

26. Klaase JM, Kroon BBR, Van Geel AN, et al. Systemic leakage during isolated limb perfusion for melanoma. Br J Surg 1993; $80: 1124-1126$

27. WHO Handbook for Reporting Results of Cancer Treatment, WHO Offset Publication No. 48, Geneva: WHO; 1979.

28. Wieberdink J, Benckhuijsen C, Braat RP, et al. Dosimetry in isolation perfusion of the limbs by assessment of perfused tissue volume and grading of toxic tissue reactions. Eur J Cancer Clin Oncol 1982; 18:905-910.

29. Wanebo HJ, Temple WJ, Popp MB, et al. Preoperative regional therapy for extremity sarcoma: a tricenter update. Cancer 1995; 75:2299-2306.

30. Rouēsse JG, Friedman S, Sevin DM, et al. Preoperative induction chemotherapy in the treatment of locally advanced soft tissue sarcomas. Cancer 1987; 60:296-300.

31. Sijens PE, Eggermont AMM, Van Dijk P, et al. ${ }^{31} \mathrm{P}$ magnetic resonance spectroscopy as predictor for clinical response in human extremity sarcomas treated by single dose TNF $\alpha+$ melphalan isolated limb perfusion. NMR Biomed 1995; 8:215-224.

32. Nieweg OE, Pruim J, Hoekstra HJ, et al. Positron emission tomography with fluorine-18-fluorodeoxyglucose for the evaluation of therapeutic isolated regional limb perfusion in a patient with soft-tissue sarcoma. J Nucl Med 1994; 35:90-92.

33. Thom AK, Alexander HR, Andrich MP, et al. Cytokine levels and systemic toxicity in patients undergoing isolated limb perfusion with high-dose tumor necrosis factor, interferon gamma, and melphalan. J Clin Oncol 1995; 13:264-273.

34. Swaak AJG, Liénard D, Schraffordt Koops H, et al. Effects of recombinant tumour necrosis factor (rTNF- $\alpha$ ) in cancer. Observations on the acute phase protein reaction and immunoglobulin synthesis after high dose recombinant TNF- $\alpha$ administration in isolated limb perfusions in cancer patients. Eur J Clin Invest 1993; 23:812818.

35. Lejeune FJ, Liénard D, Eggermont AMM, et al. Clinical experience with high-dose tumor necrosis factor alpha in regional therapy of advanced melanoma. Circ Shock 1994; 43:191-197.

36. Hill S, Fawcett WJ, Sheldon J, et al. Low-dose tumour necrosis factor $\alpha$ and melphalan in hyperthermic isolated limb perfusion. $\mathrm{Br}$ J Surg 1993; 80:995-997.

37. Eggermont AMM, Schraffordt Koops H, Lienard D, et al. Isolated limb perfusion with high dose tumor necrosis factor- $\alpha$ in combination with interferon- $\tau$ and melphalan for irresectable extremity soft tissue sarcomas: a multicenter trial. J Clin Oncol 1996; 14:26532665.

38. Liénard D, Eggermont AMM, Schraffordt Koops H, et al. TNF in isolated limb perfusion for treatment of locally advanced melanoma. Eur Cytokine Netw 1996; 7:299 (abstract).

39. Manusama ER, Nooijen PTGA, Stavast J, et al. Synergistic antitumour effect of recombinant tumor necrosis factor $\alpha$ with melphalan in isolated limb perfusion in the rat. Br J Surg 1996; 83:551-555.

40. Posner M, Liénard D, Lejeune FJ, et al. Hyperthermic isolated limb perfusion (HILP) with tumor necrosis factor (TNF) alone for metastatic intransit melanoma. Proc Am Soc Clin Oncol 1994; 13:1351 (abstract).

41. Nooijen PTGA, Manusama ER, Eggermont AMM, et al. Synergistic effects of TNF $\alpha$ and melphalan in an isolated limb perfusion model of rat sarcoma: a histopathological, immunohistochemical and electronmicroscopical study. Br J Cancer 1996 (in press).
42. Manusama ER, Stavast J, Durante NMC, et àl. Isolated limb perfusion in a rat osteosarcoma model: a new anti-tumour approach. Eur J Surg Oncol 1996; 22:152-157.

43. Spriggs DR, Sherman ML, Michie H, et al. Recombinant human tumor necrosis factor administered as a $24 \mathrm{~h}$ intravenous infusion. A phase I and pharmacologic study. J Natl Cancer Inst 1988; 80:10391044.

44. Blick MB, Sherwin SA, Rosenblum M, et al. A phase I trial of recombinant human tumor necrosis factor in cancer patients. Cancer Res 1987; 47:2986-2989.

45. Feinberg B, Kurzrock R, Talpaz M, et al. A phase I trial of intravenously administered recombinant tumor necrosis factor alpha in cancer patients. J Clin Oncol 1988; 6:1328-1334.

46. Carswell EA, Old LJ, Kassel RL, et al. An endotoxin induced serum factor that causes necrosis of tumors. Proc Natl Acad Sci U S A $1975 ; 72: 3666-3670$.

47. Sugarman BJ, Aggarwal BB, Hass PE, et al. Recombinant tumor necrosis factor-alpha: effects on proliferation of normal and transformed cells in vitro. Science 1985; 230:943-945.

48. Renard N, Liénard D, Lespagnard L, et al. Early endothelium activation and polymorphonuclear cell invasion precede specific necrosis of human melanoma and sarcoma treated by intravascular highdose tumour necrosis factor alpha (TNF $\alpha$ ). Int J Cancer 1994; 57:656-663.

49. Renard N, Nooijen PTGA, Schalkwijk L, et al. VWF release and platelet aggregation in human melanoma after perfusion with TNF $\alpha$. J Pathol 1995; 176:279-287.

50. Nooijen PTGA, Eggermont AMM, Verbeek MM, et al. Transient induction of E-selectin expression following TNF-based isolated limb perfusion in melanoma and sarcoma patients is not tumor specific. J Immunother 1996; 19:33-44.

51. Watanabe N, Niitsu $\mathrm{Y}$, Umeno H, et al. Toxic effect of TNF on tumor vasculature in mice. Cancer Res 1988; 49:2179-2183.

52. Nawroth P, Handley D, Matsueda G, et al. TNF/Cachectin-induced intravascular fibrin formation in Meth-A fibrosarcomas. J Exp Med 1988; 168:637-647.

53. Eggermont AMM, Schraffordt Koops H, Lienard D, et al. Angiographic observations before and after high dose TNF isolated limb perfusion in patients with extremity soft tissue sarcomas. Eur J Surg Oncol 1994; 20:323 (abstract).

54. Manusama ER, Stavast J, Marquet RL, et al. Total body irradiation (TBI) attenuates antitumor effects of TNF $\alpha$ in isolated limb perfusions (ILP) in the rat. Eur J Surg Res 1995; 27:110 (abstract).

55. Prograbniak HW, Witt CJ, Terrill R, et al. Isolated lung perfusion with tumor necrosis factor: a swine model in preparation of human trials. Ann Thorac Surg 1994; 57:1477-1483.

56. Fraker DL, Alexander HR, Thom AK. Use of tumor necrosis factor in isolated hepatic perfusion. Circulatory Shock 1994; 44:45-50.

57. Vries de MR, Borel Rinkes IHM, Wiggers T, et al. Hyperthermic isolated hepatic perfusion with TNF $\alpha$ with and without melphalan in pigs. Eur J Surg Res 1995; 27:81 (abstract).

58. Veen van de AH, Manusama ER, Kampen van CA, et al. Tumor Necrosis Factor- $\alpha(\mathrm{TNF} \alpha)$ in isolated kidney perfusions in rats: toxicity and antitumor effects. Eur J Surg Oncol 1994; 20:404405.

\section{Discussion}

Professor N. S. WILliams (Whitechapel, United Kingdom): I found this paper very interesting, but you used hyperthermia as well as a combination of TNF melphalan, and it is difficult to understand why you are so confident that it is the TNF that is having the effect, because hyperthermia alone is known to 